\title{
Oral antibiotic cure of staphylococcal endocarditis
}

\author{
N. D. BURMAN \\ M.B., Ch.B.
}

\author{
H. S. JoFFE \\ M.B., Ch.B., M.Med.(Paed.)
}

\author{
C. WATSON \\ M.R.C.(Path.) \\ University of Cape Town
}

\begin{abstract}
Summary
There are as yet few clinical reports of successful treatment of bacterial endocarditis with oral antibiotics, or of the use of the rifamycins in non-tuberculous infections. A case of refractory staphylococcal endocarditis successfully treated with oral rifampicin and erythromycin is presented. The availability of effective oral antibiotic therapy avoids the serious difficulties of long term parenteral antibiotics and offers a hopeful alternative to emergency cardiac surgery in this condition.
\end{abstract}

\section{Introduction}

Prolonged intravenous antibiotic therapy for bacterial endocarditis may become difficult to administer in the patient whose superficial veins have been exhausted. Surgically implanted venous catheters and repeated intramuscular injections have their own complications and discomfort. There are few reports (Peard et al., 1970) of patients successfully treated with oral antibiotics. A patient with resistant staphylococcal endocarditis cured by oral rifampicin plus erythromycin is described.

\section{Case report}

P.M., a 9-year-old boy, was admitted to the Red Cross War Memorial Children's Hospital on 9 November 1970. Cyanotic congenital heart disease had first been diagnosed at 2 weeks of age, and cardiac catheterization at 2 years demonstrated transposition of the great arteries with pulmonary stenosis and a ventricular septal defect (VSD). At the age of 7 years a successful Rastelli operation was performed including insertion of a dacron patch and an aortic homograft. The post-operative course was uneventful, and he led a normal life for the next 18 months, without any antibiotic therapy. His current admission followed a week-long history of sore throat, fever, dyspnoea and mental confusion.
Examination revealed a small child weighing $21 \mathrm{~kg}$. He was stuporose and restless with a temperature of $40^{\circ} \mathrm{C}$, mild scleral jaundice, peripheral cyanosis and marked clubbing of the fingers, but no splinter haemorrhages. He had bilateral follicular tonsillitis and a herpes stomatitis. The fundi and peripheral pulses were normal. His pulse rate was $140 / \mathrm{min}$ and he was tachypnoeic. There was no overt cardiac failure, but there was clinical left ventricular hypertrophy and a grade $5 / 6$ ejection systolic murmur maximal at the pulmonary area. He had signs of bilateral pulmonary consolidation and a $3 \mathrm{~cm}$ soft tender hepatomegaly, but no splenomegaly. Other systems were normal.

Investigations included a haemoglobin of 12.6 $\mathrm{g} / 100 \mathrm{ml}$, platelet count of $13,000 / \mathrm{mm}^{3}$, white blood count of $19,600 / \mathrm{mm}^{3}$, with $88 \%$ neutrophilis, many with toxic granulations. Serum urea, electrolytes and alkaline phosphatase were normal, but the total bilirubin was $3.8 \mathrm{mg} / 100 \mathrm{ml}$ (conjugated $2.6 \mathrm{mg} / 100$ $\mathrm{ml}$ ) and the serum glutamic oxalic transaminase 199 units (normal less than 40 units). Protein electrophoresis: albumin $2 \mathrm{~g} / 100 \mathrm{ml}$; globulins, alpha $1.5 \mathrm{~g} / 100 \mathrm{ml}$, alpha $20.6 \mathrm{~g} / 100 \mathrm{ml}$, beta $0.8 \mathrm{~g} / 100 \mathrm{ml}$ and gamma $0.9 \mathrm{~g} / 100 \mathrm{ml}$. An electrocardiogram showed a mean frontal plane QRS axis of $-60^{\circ}$ and right bundle branch block. Chest X-ray showed cardiomegaly and calcification of aortic homograft (Fig. 1). Blood cultures taken on admission, and 3 days later, revealed a growth of a coagulase-positive staphylococcus aureus sensitive to cloxicillin, chloramphenicol, tetracycline, sulfadiazine, gentamicin, lincomycin, fucidin and kanamycin, but not to penicillin.

\section{Course and management}

The admission diagnosis was pneumococcal pneumonia with septicaemia. He was given oxygen, digoxin, crystalline penicillin two million units intravenously (i.v.) 6 hourly and kanamycin $100 \mathrm{mg}$ 


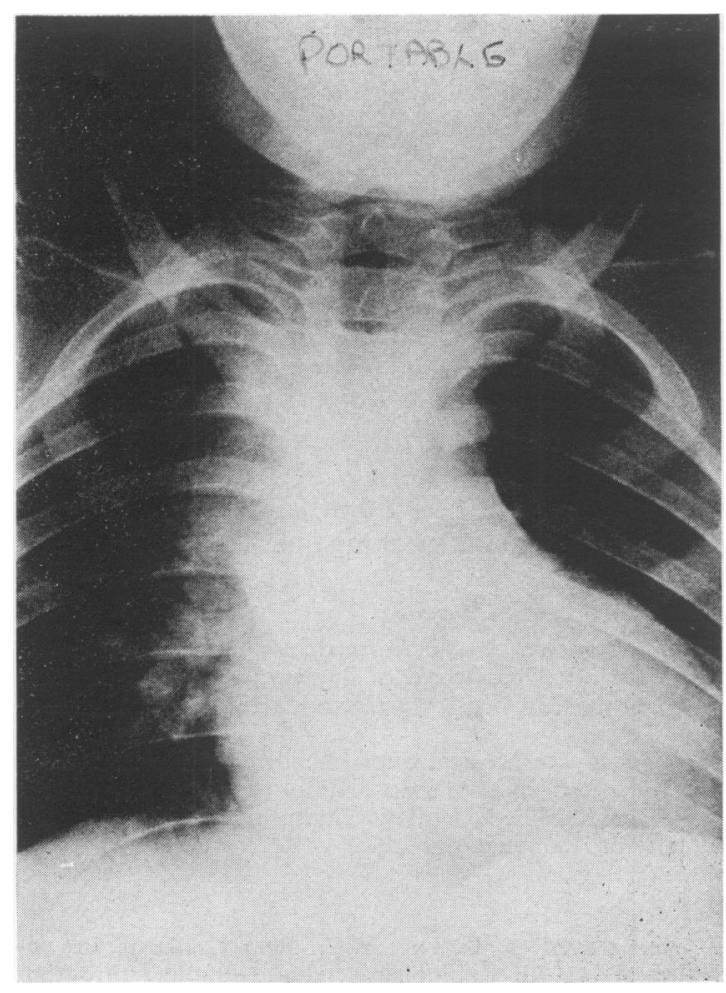

Fig. 1. Chest roentgram on admission showing calcification of the aortic homograft.

intramuscularly (i.m.) 12 hourly. Over the first $48 \mathrm{hr}$ his condition improved sufficiently for him to come out of oxygen and feed himself. However, he remained toxic and with the appearance of splinter haemorrhages on his conjunctivae and fingernails, the diagnosis of acute bacterial endocarditis became obvious.

On receipt of the first positive blood culture report, kanamycin was replaced by cloxicillin $2 \mathrm{~g}$ i.v. daily. With no reduction in pyrexia, gentamicin $60 \mathrm{mg}$ i.v. daily was added. This triple therapy still had no effect, and the gentamicin was stopped after 7 days when his blood urea had doubled to $46 \mathrm{mg} / 100$ $\mathrm{ml}$; the urea reached $70 \mathrm{mg} / 100 \mathrm{ml}$ in the fourth week, but thereafter became normal. By the fifteenth day, as his general condition was gradually improving, he was switched to procaine penicillin 600,000 units i.m. daily, and oral cloxicillin $2 \mathrm{~g}$ daily. A 9day course of chloramphenicol $2 \mathrm{~g}$ i.v. daily was added, but produced no further improvement. After a month, his pyrexia was unabated, with a white cell count of $40,000 / \mathrm{mm}^{3}$. He had progressive cardiac failure with the development of semi-lunar valve incompetence and central cyanosis. Recurrent pleural effusions were sterile on culture. With succes-

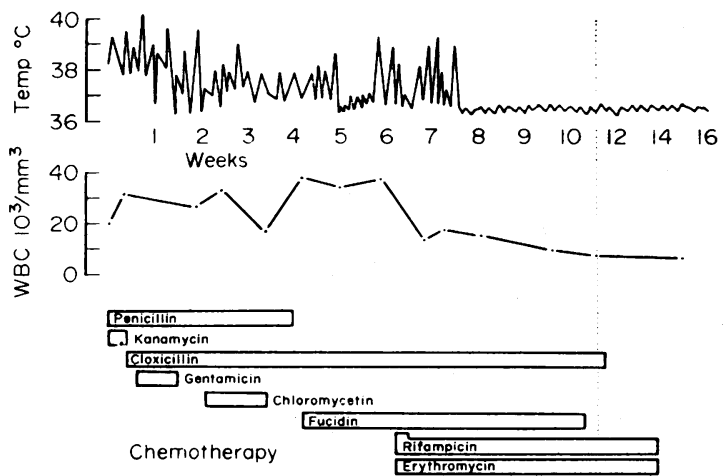

FIG. 2. Clinical course of patient with acute staphylococcal endocarditis.

sive fever crises and rigors, numerous blood cultures were taken, but these were all sterile after the first 3 days of therapy. At this stage penicillin was withdrawn completely, and oral fucidin $750 \mathrm{mg}$ daily was commenced, together with oral cloxicillin augmented by probenecid. This regime produced a short-lived remission (Fig. 2). After 40 days of uncontrolled acute endocarditis, we were loath to recommence seemingly futile multiple antibiotics via a surgically implanted catheter, without which further i.v. therapy had become impossible. Further sensitivity tests on the infecting organism were impossible since the original strain was no longer available. On the basic of a report by Peard et al. (1970) oral rifampicin $450 \mathrm{mg}$ plus erythromycin $1 \mathrm{~g}$ daily were added to the cloxicillin and fucidin. His clinical state improved within 2 days; after several days his temperature fell to normal, and his white cell count fell for the first time to $18,000 / \mathrm{mm}^{3}$ and then settled at normal levels. After 7 weeks of the new drug combination all antibiotics were finally withdrawn. No drug toxicity or side effects were encountered clinically, haematologically or biochemically over this period.

Reassessment at this stage-14 weeks after admission-showed a cheerful ambulant boy with persistent mild cyanosis and moderate clubbing. Cardiac failure was well controlled on maintenance digoxin. The systolic and diastolic murmurs at the pulmonary and mitral areas suggested stenosis and incompetence of the homograft aortic valve. Since discharge he has remained well and attends school. In view of his satisfactory general condition further reconstructive cardiac surgery has been deferred.

\section{Discussion}

Acute bacterial endocarditis, particularly after open heart surgery has a very high mortality. Fraser, Rossal \& Dvorkin (1967) had twelve deaths in fourteen cases of endocarditis in a series of 520 survivors of cardiopulmonary by-pass surgery. 
They found that antibiotic therapy was unrewarding until further surgery was performed. With the use of prosthetic materials, bacteria lodge in an avascular area on which leukocytes cannot be expected to participate in defence; thus serum antibiotic levels must be bacteriocidal rather than bacteriostatic (Carpenter \& Wallace, 1969). Even then, negative blood cultures and the disappearance of fever may indicate merely suppression and not eradication of infection.

With penicillinase producing staphylococci, it has been advocated that combinations of a penicillinase resistant antibiotic, e.g. cloxicillin, with benzyl penicillin may permit the latter to exert maximum bacteriocidal effect (Jawitz \& Brainerd, 1962). However, with acute staphylococcal endocarditis, conventional disc sensitivity tests are no guide to therapy (Peard et al., 1970; Jawitz \& Brainerd, 1962). Carpenter \& Wallace (1969) recommend that in these resistant cases combinations of antibiotics should also be tested in vitro for synergism and, if necessary, the bacteriocidal activity of the patient's serum while on antibiotics should be tested against the infecting organism.

Our patient showed little response to combined high dosage antibiotics parenterally or orally, including fucidin which achieves high blood levels given orally. Because of already prolonged parenteral therapy we sought a bacteriocidal combination which would be effective orally, without the risks of long term use of such drugs as gentamicin or chloramphenicol. Peard et al. (1970) tested a similar organism against forty-five paired combinations of nine antibiotics, and found that rifampicin and erythromycin gave the largest area of total bacteriocidal action. They stated that staphylococci are more sensitive to rifampicin than to any other antibiotic. Our patient, like theirs, responded to this combination within a week, fortunately without parenteral administration.

Few side effects have so far been reported with the rifampicin group of antibiotics (Blajchman et al., 1970), but it has been stressed that they should not be used for non-tuberculous infections except in dire necessity. While they are among the most po- tent agents yet developed against mycobacteria (Dormer \& Salinger, 1971), as well as many other bacteria, resistance to the rifamycins develops rapidly if they are used alone. In this respect we may have erred in not covering our patient with a second antituberculous drug against the contingency of coincidental tuberculosis.

Emergency surgical intervention in acute bacterial endocarditis has been recommended in the presence of a drug-resistant organism, for the development of recalcitrant infection around a mechanical prosthesis, or for acute uncontrollable heart failure (Editorial, 1968). However, in view of the poor results quoted by Fraser et al. (1967), even after repeated surgery, the use of heroic antibiotic therapy appears justifiable before undertaking operative intervention.

\section{Acknowledgments}

Cardiac surgery was performed by the Cardio-Thoracic Surgical Unit, Department of Surgery, University of Cape Town, at the Red Cross War Memorial Children's Hospital, Cape Town.

We thank the Medical Superintendent of the Red Cross War Memorial Children's Hospital for permission to publish. We thank Messrs. Lepettit Pharmaceuticals for making supplies of rifampicin available.

\section{References}

Blajchman, M.A., Lowry, R.C., Pettit, J.E. \& StradLING, P. (1970) Rifampicin-induced immune thrombocytopenia. British Medical Journal, 3, 24.

CARPENTER, C.C.J. \& WALlaCe, C.K. (1969) Bacterial endocarditis: current concepts. Bulletin of the Johns Hopkins Hospital, 124, 339.

Dormer, B.A. \& SAlINGer, P.L. (1971) A comparative trial with combinations of rifampicin, ethambutol and isoniazid (hydronsan) in previously untreated cases of pulmonary tuberculosis. South African Medical Journal, 45, 697.

EDITORIAL (1968) Emergency valve replacement in infective endocarditis. British Medical Journal, 1, 5.

FraSER, R.S., RosSALl, R.E. \& DvorkIN, J. (1967) Bacterial endocarditis occurring after open heart surgery. Canadian Medical Association Journal, 96, 1551.

JAwITZ, E. \& BRAINERD, H.D. (1962) Staphylococcal endocarditis; results of combined antibiotic therapy in fourteen consecutive cases (1956-1959). American Journal of Medicine, 32, 17.

Peard, M.C., Fleck, D.G., Garrod, L.P. \& WaterWORTH, P. M. (1970) Combined rifampicin and erythromycin for bacterial endocarditis. British Medical Journal, 4,410 . 